\title{
Influence of the Stator Winding Vibration on the Insulation System Lifetime
}

\author{
Stauber Jiř́ ${ }^{1)}$, Kuruc Tomáš ${ }^{2)}$, Pašek Roman ${ }^{3)}$, Smolík Luboš ${ }^{4)}$ and Krupauer Petr ${ }^{5)}$ \\ 1) Plzen, Czech Republic, jv.stauber@post.cz \\ 2) BRUSH SEM s.r.o. Engineering-Mechanical Design Plzen, Czech Republic, tomas.kuruc@brush.eu \\ 3) VZU Plzen, Czech Republic, pasek@vzuplzen.cz. \\ 4) VZU Plzen, Czech Republic, smolik@vzuplzen.cz \\ 5) BRUSH SEM s.r.o. Engineering-Winding Insulation Design Plzen, Czech Republic, petr.krupauer@brush.eu
}

\begin{abstract}
The article deals with establishing of natural frequencies at the stator endwinding in stage of design of the machine (generator) and then measurement of the mode shapes (modal analysis on a real machine).
\end{abstract}

Keywords - stator winding, endwinding, modal analysis, mode shape, natural frequency

\section{INTRODUCTION}

Stator winding insulation systems has been changed significantly in the last 80 years. See publication (1), where the changes are summarised since the year 1890 . The common sign is a continual change to a thinner insulation wall. It means a continual change to a higher electrical operation stress. In the beginning of el. machines manufacture the el. operation stress was below $1 \mathrm{kV} / \mathrm{mm}$, in these days the stress is around $3 \mathrm{kV} / \mathrm{mm}$ and it is steadily increasing. These changes are given by developing of materials and technology at insulation manufacturing companies and also at companies using the insulation materials (producers of el. machines).

\section{INSULATION SYSTEM - AREA OF THE MOST SIGNIFICANT CHANGES}

The high voltage insulation materials were and are still based on mica. Over years the structure has been changed from the leaf split mica to the reconstructed mica paper. The most changes were done on a carrier and on bonding systems. In the beginning the carriers and bonding resins were on a natural base. Then these were replaced by synthetic materials. Originally the shellac micafolium were replaced by the glass-mica-asphalt mica tape and combination of these materials. At the end of the 60's it was a rapid change. New materials were developed on a base of the glass cloth and epoxy (polyester) resins. This change influenced fundamentally the technique of manufacturing and also the machine designs. There were changes in a fixation of the stator winding in the slot and in the endwinding too. The higher el. stress and higher thermal conductivity influenced the usage of the machines and opened possibilities for power increasing. The changes in the insulation system continued steadily in areas of the resin composition and carriers (polyetylenterephtalat foil). At the same time there were changes in the technology equipment in insulation material manufactures and companies using the insulation materials. The result is increasing of the mean value of the chosen parameters and standard deviation decreasing. The consequence is an increasing of the el. operation stress without shortening of the insulation system lifetime.
Simultaneously the effect of each factor is changing. The el. stress is not so important factor comparison to the old original insulation systems. The mechanical stress is being more and more important that corresponds to the fixation (supporting) system of the stator winding. The endwinding vibration can be a severe harmful factor rather than el. stress of insulation. An improper design can cause a mechanical erosion of the insulation and this can result in shortening of the insulation system lifetime.

\section{FORCES ACTING ON STATOR WINDING}

The electrodynamic forces impact the stator winding in the slot. The forces are created from mutual acting of currents and scattered field in the slot. The design solution has been stabilised using flat (or flexible or conductive) materials eliminating the side clearance and using a flexible ripple spring under wedges.

In the endwinding there are dominant forces that are caused by:

- Electrodynamic forces of the double frequency created as a result of the mutual incidence of current and scattered field in the endwinding area during normal operation and during a transient state (short circuit, sudden change of load).

- Forces from thermal expansion by a load change.

- Forces from other parts of the generators transferred on the enwinding.

\section{ENDWINDING FIXATION}

A schematic layout of the stator endwinding is in Fig. 1. The stator winding is wedged in slots $\underline{\mathbf{1}}$, the wedging must ensure lasting and reliable contact with the slot wall and must enable the dilatation of the winding. The endwindings $\underline{\mathbf{2}}$ are braced mutually (with blocks made of a suitable material or with potting) and the endwindings are tightened to the supporting boards $\underline{\mathbf{3}}$.

The particular design is dependent on the cooling system and size (power) of the machine. The machines with the stator winding cooled by hydrogen must be designed in that way which enables the cooling medium to flow between the endwindings and to enable a maximum cooling surface of the endwinding. The machines cooled by water may have more massive fixation of the endwindings (potting of the endwinding, full solid supporting ring). In this case it is necessary to design the endwinding supporting system in that way which enables dilatation of the endwinding. 


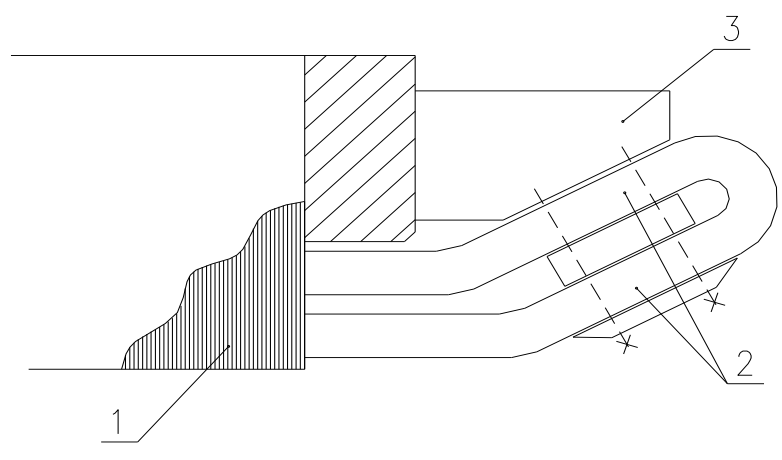

Fig. 1. Example of the stator endwinding fixation.

The bracing endwinding system must be able to catch the forces in the endwinding at transient states and simultaneously to reduce the vibration during running of the machine as much as possible. An increasing of vibration increases the initial forces acting at each single element of the bracing system and at the endwinding too resulting in loosening of the bracing elements. At first the movement causes abrasion of the bracing elements and endwinding insulation. The consequence is a damaging of the insulation resulting in an electrical breakdown (especially on the phase break or on the slot exit). The damage of the winding can be sped up by an overall loosening of the winding resulting in change of the natural frequency of the endwinding (or part of the endwinding). Then the natural frequency can be close to the frequency of the electrodynamic forces acting on the winding.

\section{CHARACTER ENDWINDING VIBRATION}

A rotating magnetic field in the generator creates forces, the radial component of the force creates a radial shape of vibration. Analogically the electrodynamic forces act in the endwiding area too. The basic shapes caused by the radial force component are in figure 2: a) 2-node, b) 4node, c) 6-node shape.
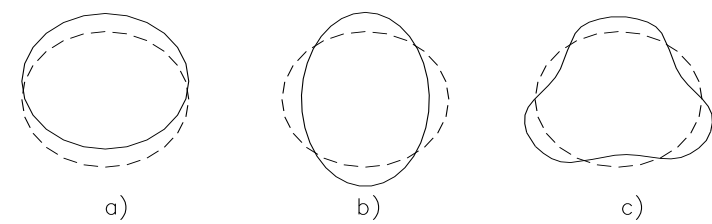

Fig. 2. Basic mode shapes displayed kvasistatic.
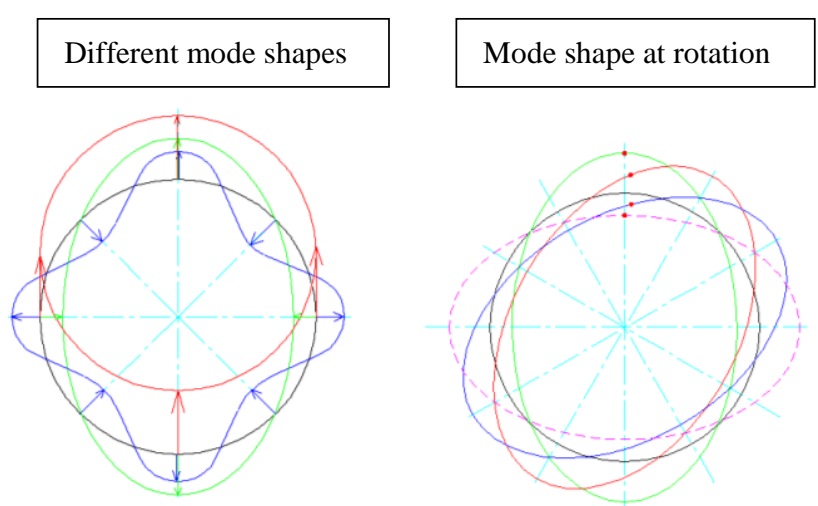

Fig. 3. Several different kinds of mode shapes (left) and mode shape at rotation (right).
The mode shapes in Fig. 2 are displayed as kvasistatic, the body is performed inside the machine (as if rotated) (see Fig. 3) where the oscillation shape is displayed in several steps. Each point of the body moves not only radially but tangentially too.

The most dangerous is the 4-node shape for a 2 pole generator. The 4-node shape is excited by the rotating magnetic field and correlated electromagnetic forces in the endwinding area. Usually the natural frequency of the 4node shape is from $130 \mathrm{~Hz}$ to $160 \mathrm{~Hz}$ for the turbogenerator stator, the natural frequency of the 4-node shape is below the double grid frequency (below $100 \mathrm{~Hz}$ or $120 \mathrm{~Hz}$ ) for the endwinding. By an improper design the natural frequency can be very close to the operating frequency and the endwinding can be at resonance. The final vibration of the endwiding is a superposition of the enforced vibration from the electrodynamic forces and it is dependent on the natural frequency of the endwinding.

\section{ENDWINDING NATURAL FREQUENCY IDENTIFICATION AT THE DESIGN STAGE}

It is possible to identify the natural frequency and mode shape by an experiment. However it is almost impossible to change the natural frequency on the complete finished machine. At the design stage it is possible to calculate the endwinding natural frequency by the FEM method. Creating of a mathematical model is difficult, especially to establish the material properties of the used components for the numerical model.

Fig. 1 does not show the real difficulty of the endwiding design. The stator coils are manufactured from several wires (lamellas) that are bonded together and then the conductor stack is wrapped with a reactoplastic insulation. The stator endwinding is from two crosswise layers, spaced with glass laminate blocks, tightened together and tightened to the stator. Some materials are strongly anisotropic. It is very difficult to create an adequate model representing the real configuration of the endwinding arrangement. Therefore it is necessary to find a simplified solution.

For establishing the simplified endwinding model it is necessary to define the substitutive material constants that would respect the anisotropic abilities sufficiently. Therefore an endwinding model has been created in a shape of a rectangular board (see Fig. 4), that represents a part of the endwinding in development.

\section{The plane model of the endwinding}

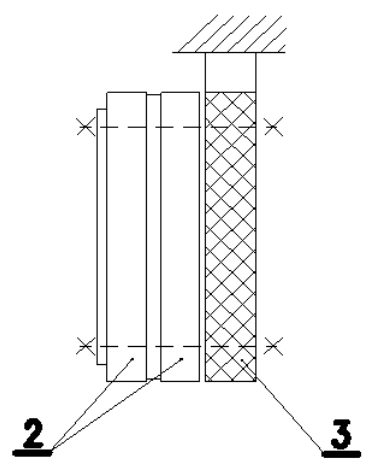

Fig. 4. Plane model of the winding with a massive support ring. 
Thereby the involute coils are transferred into straight coils. The model consists of two crosswise layers of the winding $\underline{\mathbf{2}}$ braced in the same way as the real winding. Both layers are tightened to a board $\underline{\mathbf{3}}$ modelling a supporting construction of the endwinding (for example supporting ring). Frequency-modal ability of this model was established by the experiment and calculation (FEM). The change of the material properties for the 3D computer model was provided as long until the calculated natural frequency agreed with the measured natural frequency. In this way the substitutive material abilities were established for the endwinding $\underline{\mathbf{2}}$.

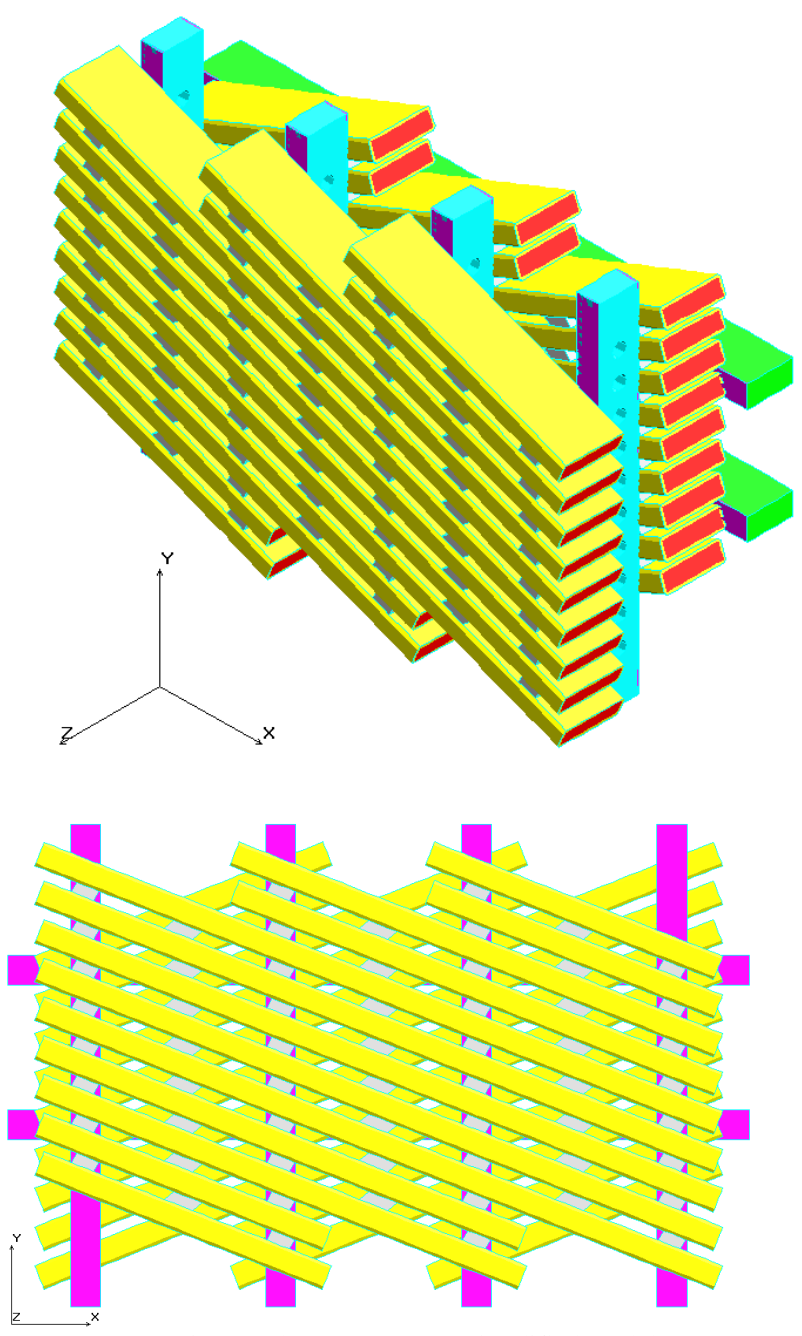

Fig. 5a, 5b. 3D computer simplified model.

Fig. 5c shows the particular model of the endwinding representing the layout of winding with the supporting boards in development. The model was freely hung on a steel tin rope.

The hanging enabled to measure the natural frequencies for each individual mode shape at the ambient temperature and at the higher temperature - see Fig. 6. In Fig. 6 there are natural frequencies corresponding to the particular mode shape for 4 different temperatures.

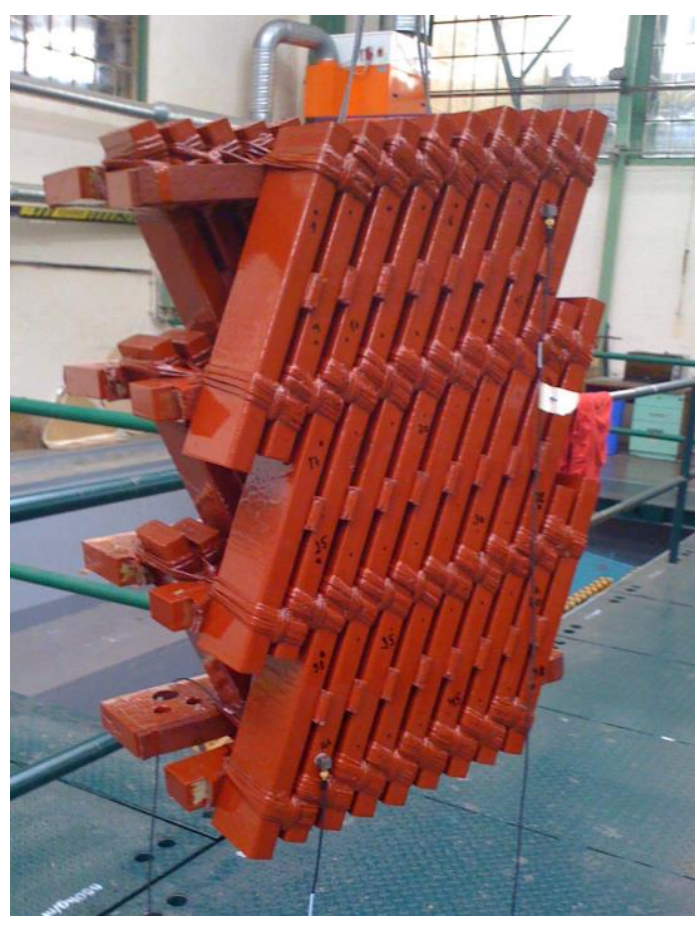

Fig. 5c. Particular model of the endwinding in development.

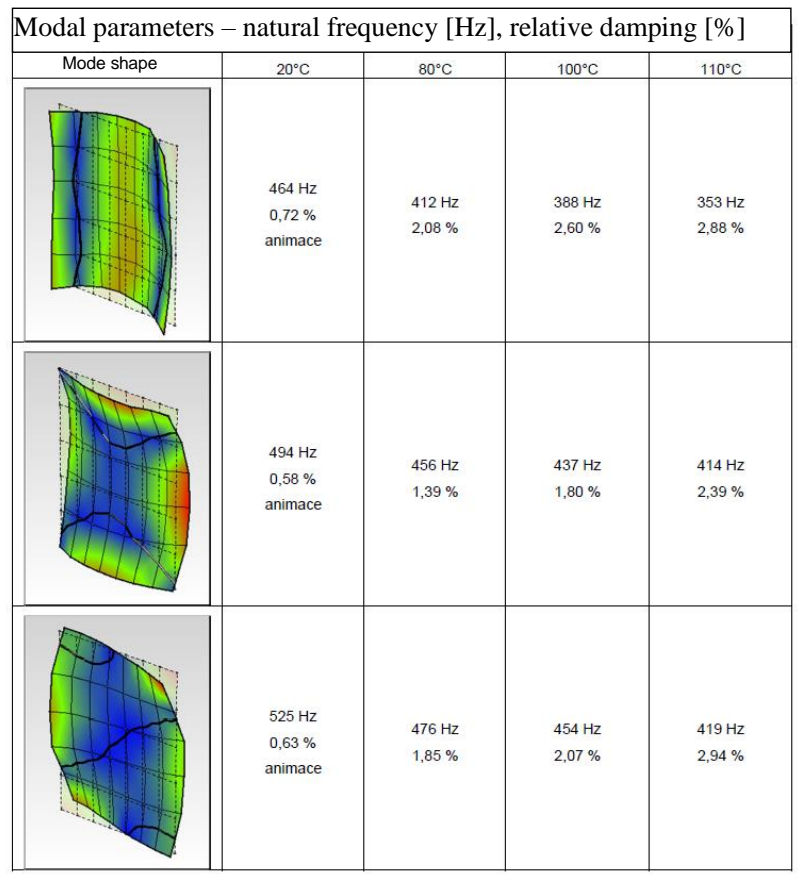

Fig. 6. Mode shapes and natural frequency at different temperatures measured by the external company VZU Plzen.

Simultaneously a computer model has been created for the flat arrangement. It was possible to change the input parameters in that way, that the calculated natural frequency corresponding to each single mode shape was identical to the measurement (modal analysis). In this way the substitutive parameters were established for the real model of the endwinding. 
Establishing of the material abilities for the endwinding will enable to create the mathematical computer model respecting the fixation of the endwinding in the design stage. This enables to know the mode shapes and its natural frequencies in the design stage. At the same time it is possible to evaluate the influence of each element (endwinding component) on the natural frequency.

\section{THE NATURAL FREQUENCY MEASUREMENT ON A REAL MACHINE}

The natural frequencies of an already manufactured endwinding (it means the natural frequency of the real mechanical structure) can be found employing an experimental modal analysis. The experimental modal analysis is analyzing the dynamic response of a system utilizing so called Frequency Response.

Functions (FRFs). The resulting FRFs will show the modal properties of the system: natural frequencies and correlating mode shapes and modal damping.

The FRF can be loosely defined as the linear relation between the excitation and vibration response:

$$
H(f)=\frac{\text { response }}{\text { excitation }}
$$

The response and excitation are usually transformed from the time to the frequency domain by the fast Fourier transform (FFT). Because both transformed spectra are complex, the frequency response function $H(f)$ is complex too. Thus it holds information about amplitudes and phases between excitation and response.

The FRF refers to a relation between just two points, which brings some drawbacks: a measurement point can be placed at a nodal line of the particular mode shape. The nodal line can be defined as the line which does not move when the structure is vibrating by the mode shape. It means that there is no vibration response at all and the corresponding natural frequency cannot be found in the FRF. Therefore the vibration response is measured in many points (see Fig. 7). In the case of the endwinding, the position and number of the measurement points are chosen in relation to which the mode shapes should be visualised: e.g. for identifying the 4-node shape (see Fig. 2) it is convenient to choose at least 8 measuring points around circumference of the winding.

The usage of the frequency response functions requires a linearity of the tested mechanical system. The linear system has got following abilities related to the modal analysis [4]:

- homogeneity - the response magnitude is linear dependant on the magnitude of the excitation force,

- reciprocity - existence of a structure symmetry, i.e. the excitation point and point where the response is measured are mutually interchangeable,

- time invariance - the dynamic parameters of the structure are constant in time. The time invariance does not have to be fulfilled e.g. during cooling of the winding.

Because of the design (see Fig. 1), the endwinding has not to be a linear system. So the results of the experimental modal analysis should be understood as a linear approximation of the real system. It is possible to suppress the non-homogeneity and time invariance influence (in case of measurement at higher temperatures) of the system by the measuring in as many points as possible (typically 15 to 24 ) in a moment. The response was measured by triaxial accelerometers traditionally. However, the practise has shown that the natural frequencies have dominant magnitudes in the radial direction. Therefore employing of uniaxial transducers is sufficient.

The excitation system is usually realised in the radial direction using an impact hammer. The radialdirection of the excitation relates to the fact that the natural mode shapes are dominant in this direction. In case a modal (e.g. electromagnetic) exciter were used for the excitation, it would be necessary to assembly the exciter in such a way that an exciter arm would be directed in the radial direction. The exciter would have to be then placed inside the winding what is technically difficult to realize.

If uniaxial sensors and an impulse hammer are used, it is possible to measure the vibration response in all measurement points in three steps (see Fig. 7). It means that during each realization of the excitation, the response is measured at all points of one circle of the net. Theoretically the excitation point may be chosen so that it is identical with the node point of some mode shape. This mode shape is very difficult to excite in this case and it could not be found (it would be a measurement error). Therefore the excitation is realised in more points which are spread out circumferentially.

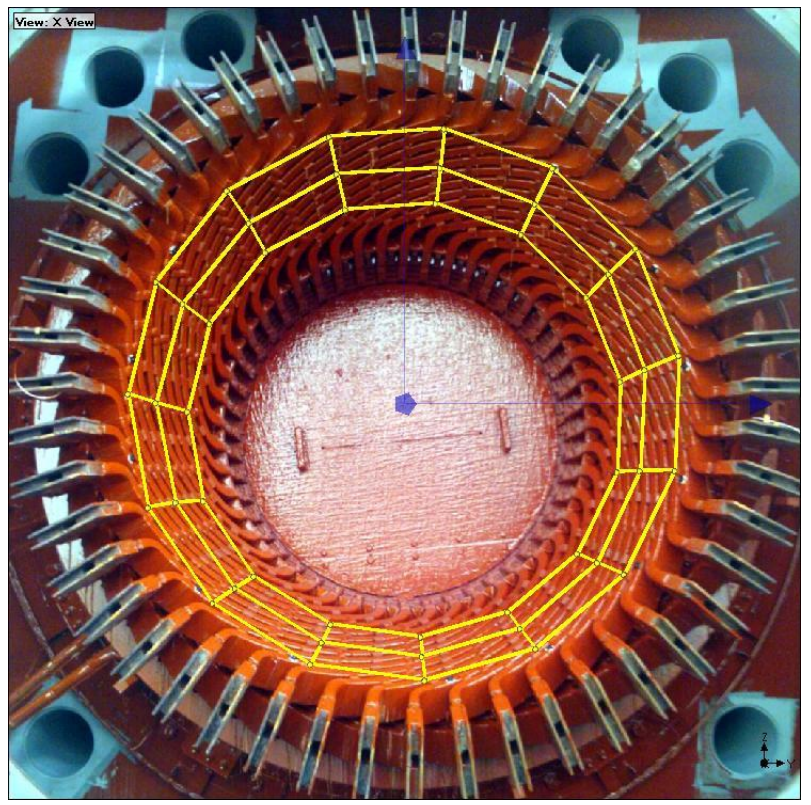

Fig. 7. Typical net of the measurement points at the endwiding (combination of the photography and computer model).

\section{COMPARISON MEASUREMENT VS. CALCULATION FOR PARTICULAR MACHINES}

In this chapter there is described a comparison between calculation and measurement of the endwinding natural frequencies for some different machines varying in the endwinding fixation (way of bracing). The arrangement of the endwinding is visible in Fig. 8. 


\section{Turbogenerator $1000 \mathrm{MW}$}

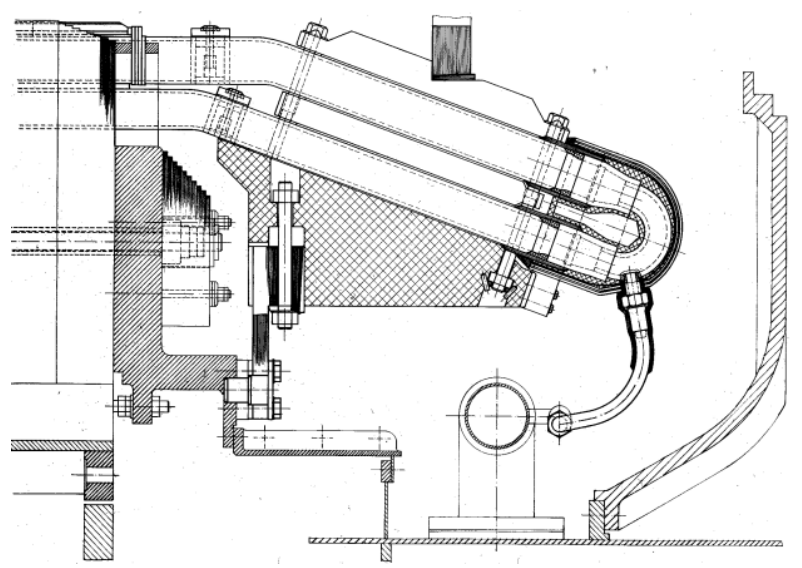

Fig. 8. Arrangement of the endwinding.

The endwinding is tightened to a massive supporting ring. The supporting ring is connected to the pressure plate with many flat springs.

The calculation of the natural frequencies was done at the end of 80 's by a mainframe computer using the program SAP 86. The results of the calculation are in Table 1.

TABLE I.

RESUltS OF CALCULATION OF NATURAL FREQUENCIES

\begin{tabular}{|c|c|}
\hline \multicolumn{2}{|c|}{ Calculation } \\
\hline Mode shape & Frequency $[\mathrm{Hz}]$ \\
\hline 2-node & 38,8 \\
\hline 4-node & 81,9 \\
\hline 6-node & 153 \\
\hline
\end{tabular}

The measurement of the natural frequencies was done in the beginning of 90's by a vibrating magnet. A response was measured by many vibration sensors placed at the circumference of the supporting endwinding ring. The measured values are in Table 2.

TABLE II.

MEASURED NATURAL FREQUENCIES FOR EACH INDIVIDUAL NODAL SHAPE

\begin{tabular}{|c|c|}
\hline \multicolumn{2}{|c|}{ Measurement } \\
\hline Mode shape & Frequency [Hz] \\
\hline 4-node & 76 \\
\hline 6-node & 138 \\
\hline 8-node & 174 \\
\hline
\end{tabular}

\section{Machine Type A 116/143 MW}

The arrangement of the endwinding is visible in Fig. 9a, $9 \mathrm{~b}$. Each endwinding is spaced by glass-laminate blocks and tightened by a glass rope to the supporting boards. The boards are tightened to a pressure plate of the magnetic core.

This calculation ends an effort for modelling of the endwinding in the design stage. All measured machines were calculated too and it was done a comparison between measurement and calculation. It was proved that it is possible to establish the 4-node shape very accurately by the calculation.

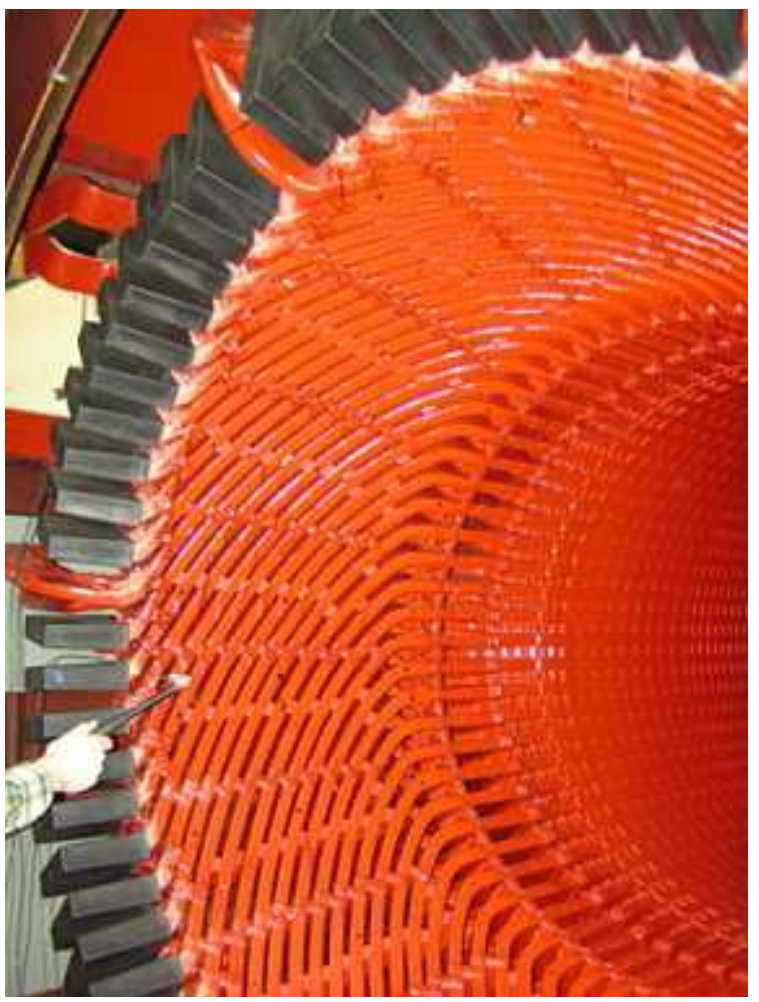

Fig. 9a. Modal analysis measured at the real endwinding.

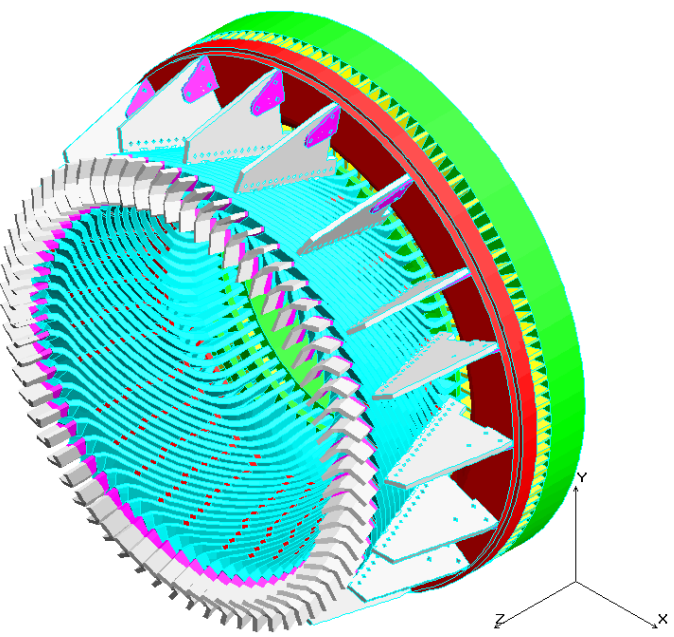

Fig. 9b. FEM model. 


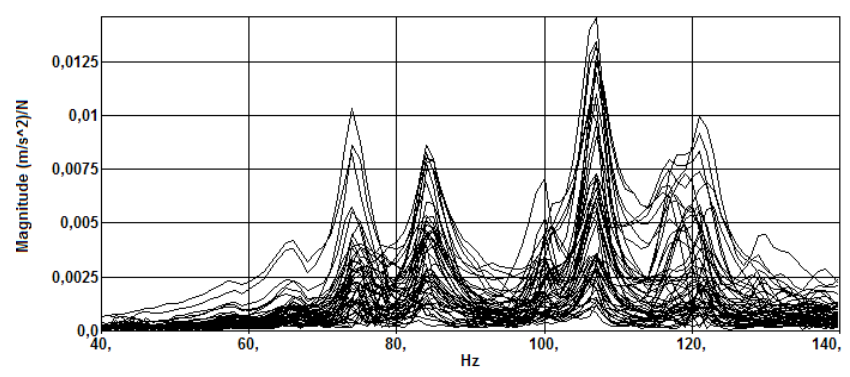

Fig. 10. Measured frequency characteristic.

Results from the modal analysis by calculation and by measurement are in Table 3.

TABLE III

RESULTS FROM MODAL ANALYSIS

\begin{tabular}{|c|c|c|}
\hline \multicolumn{2}{|c|}{ Calculation - COSMOS } & Measurement \\
\hline Mode shape & Frequency $[\mathrm{Hz}]$ & Frequency $[\mathrm{Hz}]$ \\
\hline 4-node & 85,1 & 84,0 \\
\hline 6-node & 94,5 & 106,9 \\
\hline 8-node & 104,4 & 119,0 \\
\hline
\end{tabular}

Values of the calculated and measured frequencies are in Table 3. For the 4-node shape they are around $85 \mathrm{~Hz}$ and we have very good conformity for this shape between calculation and measurement. Not such good conformity is for higher mode shapes. However the most important is the 4-node shape and its natural frequency. For a better understanding of the mode shape, an animation for 4-node shape and 6-node shape is in enclosure [2], [3].

\section{CONCLUSION}

In the article it is presented a summary of the basic methods for establishing the natural frequencies for the endwinding. The establishing methods can be used at the design stage of the winding including calculation (computer simulation) and measurement on a model. Then the calculated results are compared with the real measurement on a real machine. The natural frequency is dependent on the endwinding fixation (supporting) system. As shown the common generators (manufacturing el. energy) run at the over-resonance zone. This article does not deal with some special machines (as a short circuit generator) which work at the under-resonance zone.

\section{REFERENCES}

[1] Glew G. N., „The next Generation“ - Review of the Factors Influencing the Output of Electrical Machines in the new Milenium, s.231-242, ISUCON/ISOTEC '98 The 8th BEMA International Electrical Insulation Conference.

[2] Stauber J., Sládek V., Krupauer P. Zachycení sil působící na statorová vinutí extrémně namáhaných točivých strojů. Elektroscope č II / 2009. Website link: https://otik.uk.zcu.cz/bitstream/handle/11025/547/r3c2c4.pdf?seque nce $=1$

[3] Appendix [see the next page].

[4] Allemang R. J., Brown D. L., Rost R. W. Experimental Modal Analysis and Dynamic Component Synthesis, Volume II. Cincinnati: University of Cincinnati, 1987.

http://www.dtic.mil/dtic/tr/fulltext/u2/a195145.pdf 


\section{Appendix}

\begin{tabular}{|l|l|l|}
\hline Type A 116/143 MW & 4-node shape \\
\hline FEM model & Calculation $85 \mathrm{~Hz}$ & Measurement $84 \mathrm{~Hz}$ \\
\hline
\end{tabular}
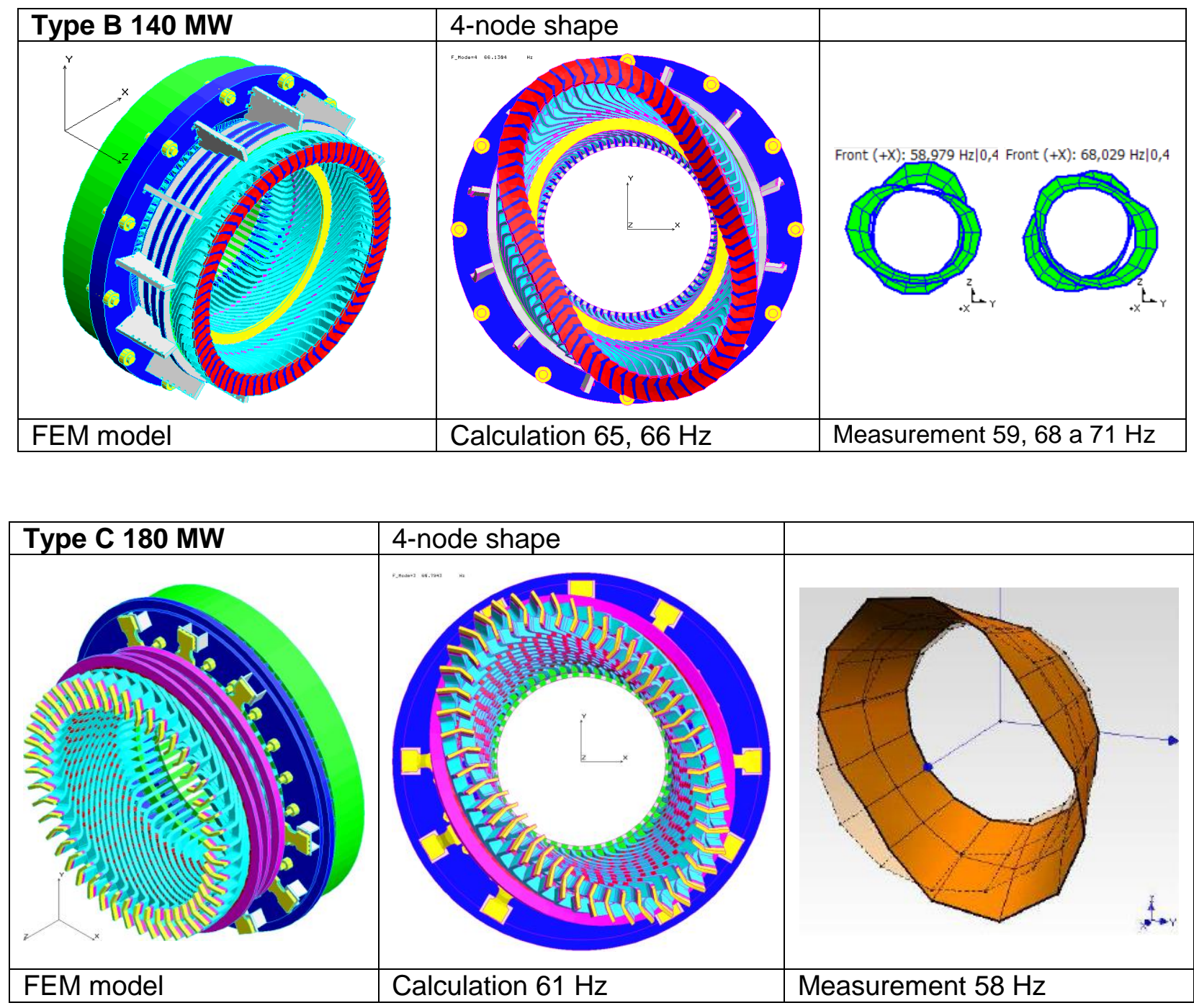

All the models were calculated for the NDE side of the machine. The agreement between calculation and measurement is satisfactory. In case of more natural frequencies for the 4-node shape the calculation is somewhere in the middle of the measured interval for the 4-node shape. The target of the calculation is to show the correctness of the design. It means that the natural frequency is not close to the double operating frequency. 